DOI: https://doi.org/10.47405/mjssh.v6i4.758

\begin{tabular}{|c|c|}
\hline 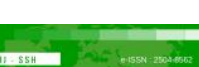 & Malaysian Journal of Social Sciences and Humanities (MJSSH) \\
\hline Malaysian Journal of & Volume 6, Issue 4, April 2021 \\
\hline (MJ. SSH) & e-ISSN : 2504-8562 \\
\hline & $\begin{array}{l}\text { Journal home page: } \\
\text { www.msocialsciences.com }\end{array}$ \\
\hline
\end{tabular}

\title{
A Daughter Not a Son as Predictor of Reggio Emilia Early Childhood Development Acceptance: Paradigm Shift in Households of Rural Areas in Northern Nigeria
}

\author{
Ibrahim Abdullahi', Zumilah Zainalaludin², Laily Hj. Paim², Mariani Mansoor² \\ ${ }^{1}$ School of Arts and Social Sciences, Isa Kaita College of Education, Dutsinma, Katsina State, Nigeria \\ ${ }^{2}$ Faculty of Human Ecology, Universiti Putra Malaysia (UPM), Malaysia \\ Correspondence: Ibrahim Abdullahi (babanaliyu@gmail.com)
}

\begin{abstract}
Having daughters, not sons to predict accepting educational thought for children may be controversial in a patriarchal society, whiles in the actual sense is merit. This is so, as society first, perceived daughter and son from traditional gender ideology instead of the human capital view. Patriarchal society feels guilty when daughters turn out as determined, assertive, and competent than sons. This paper explores predictors of Reggio Emilia Early Childhood development (REA-ECD) acceptance, as a paradigm shift to educating daughters and sons equally in rural households' basis for gender development. A paradigm shift is a changing thought from a traditional belief to a reality of life in society. The paper draws analysis on collected data from 216 households in Binary Logistic Regression (BLR). It identified daughters as a predictor of high REA-ECD acceptance in rural northern Nigeria. The paper constructed a household background Models with the conclusion that breakthrough may be through curtailing traditional gender-based stratifications daughters instead of sons predicted RAEECD acceptance. Therefore, the patriarchal system may erode through gender development education, and future mothers might have increased in human capital quality. This may be easier with the provision of policies, studies, and indigenous knowledge and skills improvement.
\end{abstract}

Keywords: daughters, sons, acceptance, children education, rural households

\section{Introduction}

The early childhood development (ECD) is critical for sustainable and gender development of any country in the world.The ECD prepare children for school readiness, ability to be resilience, as it is one of the major determinants of individuals future success and societal development (Alizadeh et al., 2011; Fernandez, 2017; Fairani \& Mariani, 2016; Gandini, 2011; Udenigwe, 2013; Ejieh, 2006; Moss, 2006). The rural societies being the largest in the developing regions, the parents' acceptance of early childhood development for their daughters and sons in developing countries is essential(Aisha, 2016; Anne, 1998). Gendered early childhood development was proved successful in the developed global communities (Alizadeh et al., 2011; Fernandez, 2017; Fairani \& Mariani, 2016; Gandini, 2011; Udenigwe, 2013; Ejieh, 2006; Moss, 2006; Santín \& Torruella, 2017). Reggio Emilia Approach (REA-ECD) is one of the major gendered ECD approaches used in the developed regions of Europe and American and appeared to be successful in other parts of the world including northern Nigeria with its acceptance by parents. The REA-ECD appeared asa notable conducive approach in which the 
skills for gender development can be acquired by children in REA-ECD centres and schools (Pence \& Ashton, 2015). Ironically for a long time in many rural areas of the developing countries and regions, this opportunity is neglected (Nupponen, 2005; Nura \& Adamu, 2017; Meryem, 2018). Therefore, This study aims to explore and examines households' backgrounds variables to identify the predictors of parents acceptance on the enrolment of their daughters and sons in REA-ECD program.

\section{Literature Review}

The literature about the ECD phenomenon in rural areas despite its importance in healthy gender relationship and development is very scanty (Anna, 2010) as if there were no important acceptable number of human being therein. The work of literature about the phenomena of ECD, its approaches and practices are more common within the scope of urban context all over the world (Amali et al., 2016; Ejieh, 2006; Lella Gandini, 2011; Moss, 2006; Odiagbe, 2015; Salami et al., 2016; Udenigwe, 2013; UNESCO, 2007). The awareness about ECD and its impact on gender development among children by parents in rural areas need to be considered as important issues by both researchers and development partners (Amali et al., 2016; Sadker David et al., 2014; Ejieh, 2006; Moss, 2006; Udenigwe, 2013; UNESCO, 2007). This is necessary considering vital roles it plays in the individuals' life and societal development as well as nations building (Odiagbe, 2015; Gandini, 2011; Udenigwe, 2013). Importantly, there is a need to consider a large number of boys and girls population in rural areas globally (Jackie, 2006). The parents have roles to play on children right to education, and national development (UNESCO, 2007). The teaming children population in rural areas all over the world need to be considered with the ECD centres (Anna 2010; Rinaldi et al., n.d.; Nura and Adamu 2017; Salami, Childhood, and Unit 2016; Roberta 2000). From the literature, educating the children at an early age within the healthy gendered norms and values would ensure rapid and sustainable national development. Possibly, the appearance of REA-ECD and its subsequent acceptance by the parents of children with clear cutdown in gender discrimination may be what encouraged governments and development practitioners and partners to put and invest more efforts and resources (Miatta, 2017; UNECEF, 2015; UNESCO, 2019; UNESCO, 2007) in the development of the program.

This study in comparison to what is available in related literature explores and examines households' backgrounds variables and examine the parents' acceptance predictors on the enrolment of their daughters and sons in REA-ECD program. Furthermore, the study identifies and presents the remarkable predictors of high REA-ECD acceptance among the examined variables. The household backgrounds measured as the independent variable are studied by other scholars in various researches. Example, these variables were studied in the research of Adamu (2017) when reported variables on willingness to pay for conservation. The variables of household background in his study were statistically significant but mostly negative to a willingness to pay for conservation. There are also other studies reported the household background with mixed findings that make the studies on the household variable inconclusive. Adamu finding was consistent with (Surendran \& Sekar, 2010). The number of children in households was also studied in a family profile by Zumilah (2010). In households, there was an important positive impact of a parent in the overall experience of the children (Zumilah, 2010) especially mothers. According to her, by implication as mothers in rural areas are facing household-motherhood conflict. They were left busy with childcare and thinking of their schooling, at the same time experiencing inadequate funds (Zumilah, 2010), for their daily needs.

Therefore, REA-ECD as gendered ECD program, in its nature seems to improves school readiness, schooling ability and resilience of both sexes of children as they are in collaboration with parents and teachers in the learning process. This is one of the best ways to determine the future educational success of children and the entire society in face of development (Alizadeh et al., 2011; Fernandez, 2017; Fairani \& Mariani, 2016; Gandini, 2011; Udenigwe, 2013; Ejieh, 2006; Moss, 2006). The literature about this phenomenon in rural areas is very scanty (Anna, 2010) as if there were no important acceptable number of human being therein. The literature about REA-ECD phenomena, approaches and practices are not mostly common among scholars and writers on the rural context, however, the scope ECD mostly covered urban context all over the world (Amali et al., 2016; Ejieh, 2006; Lella Gandini, 2011; Moss, 2006; Odiagbe, 2015; Salami et al., 2016; Udenigwe, 2013; 
UNESCO, 2007). The awareness of rural parents about REA-ECD impact on gender development need to be considered as important by both researchers and development practitioners (Amali et al., 2016; Sadker David et al., 2014; Ejieh, 2006; Moss, 2006; Udenigwe, 2013; UNESCO, 2007). This is because the rural areas with the largest number of children, the adults' acceptance of the REA-ECD program for children in this regard have greater roles on their education and gender development (UNESCO, 2007) process.

Relating parents with rural REA-ECD, especially women encouraged governments and development partners to invest more resources and efforts (Miatta, 2017; UNECEF, 2015; UNESCO, 2019; UNESCO, 2007). This is very cleared in Katsina state and other selected states in northern Nigeria for piloting REA-ECD program. As teaming children in rural areas were considered with this opportunity for development (Anna, 2010; Nura \& Adamu, 2017; Salami et al., 2016), it imperative to investigate how parents considered and accepted the REA-ECD based on the sex of their children and their enrolment in the program as prompted by this study.

\section{Theoretical Basis}

This study was based and uses gender role theory by Lindsey and Mize (2001), which explain parents' expectations about their children roles (masculine and feminine), particularly the behaviours portrayed in the parents-child-learning roles. The theory underscores the importance of societal gender roles in this research. The study of Zumilah (2010) describes societal expectation from female and male parents, as being either a masculine or feminine. This foundation was due to the inclusion of gender analyses in identify predictor of REA-ECD acceptance between the daughters and sons among the variables of the study. This is because the theory ascribed that, one being certain sex does not mean he or she might have a self-assured way of living in their choice (Alvergne et al., 2007; Butler, 2004; Carter, 2014; Fasona, 2014; Jorge et al., 2017; Kretchmar, 2009; NECE, 2016; Sumita Parmar, 1996). This shows gender roles are controlled by both individuals but mostly by society (Butler, 2004; Christman \& McClellan, 2012) Therefore, an individual must portrait independent identity to remain he or she within the societal culture (Carter, 2014).

The study also observes some difficulty to separate desired life of individual males and females from the life of a given society in which they are living (Cockerill, Chilton \& Hutchinson, 2007; Cox \& Heck, 1998; Dannhaeuser, 1993). This issue has perpetuated more in the life of rural society (Ijeoma, 2017). Probably, is due to their culture of rurality and rural poverty, gender favouritism and environmental atmosphere (Mader, 2013; Ismail, Masud \& Zainalaludin, 2015; Gikonyo, Zainalaludin, $\&$ Masud, 2006). To speak on the gender roles boundary in some society seem very much strange. In some parts of Asia like Malaysia, this is becoming less strange when realizes that, these social norms were constituted and hold as desired but were not originated in the individual personhood. (Zakiah et al., 2015). This may be part of the traditional gender roles as expressed in (Aisha \& Yahuza, 2018; Butler, 2004; Ibrahim et al., 2015; Zumilah, 2010) that, men were assumed and considered strong, hardworking, and intelligent in control of the environment. In most rural areas their environments include women, children and all their activities within and outside the home (Abbas \& Bukar, 2017; Abdullahi et al., 2013; Amina, 2015). Yakubu (2017) has reported confirming that, women expectations in most rural society were nurturing children, and caring roles at home and beyond (Zumilah, 2010). However, it is an irony that women nurtured and cared for children and others (UNICEF, 2018), but the men are in control of resource and decisions making (Ibrahim, 2014).

The societies in rural areas of northern Nigeria have their conservative nature and rigidity about the two-child sex. The rural societies' conservative nature was described by (Zumilah, 2010) as very hard to change. For example, in rural areas of Katsina, there is a historic problem on the acceptance to enrol and send children, particularly girls into formal school system (Abdullahi \& Maiunguwa, 2014; Abdullahi, Zainalaludin \& Paim, 2013; Garba, 2017; Ibrahim, 2014; Mohammed, Nggada \& Abdullahi, 2013; Wycliff, 2014). This is because the rural people of Katsina state for long believed that, western education is an immorality gateway (Wycliff, 2014; Mohammed, Nggada \& Abdullahi, 2013; Garba, 2017; Odiagbe, 2015). Furthermore, the children right to education was left in the hands 
of their parents, no functional constituted laws that enforced parents to educate children (Abdullahi et al., 2013; Garba, 2017; Ibrahim, 2014; Mohammed et al., 2013; Wycliff, 2014). Therefore, with the acceptance of the REA-ECD, this study aims to explore daughters and sons among the predictor variables of the REA-ECD acceptance among rural households in Katsina state northern Nigeria.

\section{Methods}

The research design in this study was exploratory correlation as suggested by (Conboy et al., 2012; Gliner et al., 2011; Navarro, Sada \& Maldonado, 2007; Cohen, Manion \& Morrison, 2007). The design was used in the type of research methods in which the hypothesis of the research was to be tested based on the existing theories (Hair, et al., 2010). Conboy et al. (2012), have also established that this type of research design is commonly used when involved collecting and analysing numerical data. A combine research design could be used to achieve an objective in research (Fraenkel, Wallen, and Hyun 2011). This justified the use of the exploratory-correlation design in this study. Also, the design is appropriate as it allows gathering data from a large sample and remote destinations that allow the generalization of the finding to a larger population of the study(Creswell \& Clark 2017).The identified and defined population of a study is what (Hashim, 2010; Banerjee \& Chaudhury, 2010) refers to as "target population" of the study. Therefore, the target population of this study were parents of children in rural areas of northern Nigeria where there are established REA-ECD centres. The population of this study is specifically those parents who agree with and accepted to enrol their children in REA-ECD program centres in Katsina state. Therefore, these parents are residing, in remote and various rural areas where they born and brought up their children, who they agree and accepted to enrol their children in REA-ECD program centres, they were considered as the population of this study.

\section{Population of Study}

These populations were distributed within various localities across the 34 local government areas (LGAs) in the three senatorial zones of Katsina state. The design used is appropriate as it allows gathering data from a large sample and remote destinations. This also allows the generalization of the finding to a larger population of the study. One common characteristic of exploratory-correlational research design is to choose a sample from a large population like in this study and generalization of the finding (Creswell \& Clark, 2017). Other past studies used exploratory-correlational design in studying similar factors in technology acceptance and explore the relationship between several variables in their studies (Al-Sayyed \& Abdalhaq, 2016; Alharbi \& Drew, 2014; Alto et al., 2018; Dermont et al., 2017; Komendantova \& Battaglini, 2016; Lim \& Ting, 2012; Liu, 2014; Wersebe et al., 2017). Therefore, this study found exploratory-correlational research design on the population as the most appropriate to achieve the objectives (Abu-Dalbouh, 2013). Also, the scoping study was conducted earlier to gather supportive evidence and confirming the status of this new and the not wellresearched phenomena REA-ECD in developing region of Africa under study (Suzana et al., 2012). It normally helps to explain as planned the proposed researches or suggest other elements toward solving the identified issues. Scoping study provides additional information from individual opinions about the subject under the study (Arthur, 2018). As earlier stated, the REA-ECD is a new program, launched in 2015, the information about its acceptance and success is still not adequate. Therefore, scoping study as a popular approach in understanding the research context was used in this context besides the review (Wallang 2018; Abdu, Hashim \& Asnarulkhadi, 2014).

\section{Sampling Procedure}

Throughout the sampling process, random selections were used. Firstly, the central senatorial zone with the eleven (11) LGAs, was randomly selected, and later, six (6) LGAs out of these were also randomly selected based on zoning. The total population of 48, 479 from the selected villages with REA-ECD centres in the selected LGAs were identified. The random selection of Katsina central and subsequent selection of six LGAs was based on two reasons. Firstly, unique and uniformity of the population characters(Fraenkel, Wallen \& Hyun, 2011), throughout the Katsina state. Secondly, 
conducted based on zoning (Gliner, Morgan \& Leech, 2011), using the zonal education directories of the senatorial zones in Katsina state. From these populations, the accurate study sample size was determined. In drawing the sample size in a study, Banerjee and Chaudhury (2010) dan Bekker-Grob et al. (2015) suggestions were considered. Their view was stressed by Fraenkel et al. (2011) that to determine sample size, researchers must refer to the established tables and formulas as in (Creswell \& Clark, 2007; Fraenkel et al., 2011). The sample size of this study determined after considering the established tables of Krejcie and Morgan (1970), Yamane (1967) and Cochran (1977) sampling techniques as in Table 1 below. There are 381-394 samples required based on considered tables in this study. However, 432 samples of 50:50 female and male parents from 216 households were considered, including an additional 11 per cent margin error in the samples. Table 1 below presents the required sample size determinants considered in the sampling procedure.

Table1: Required Samples Size Determinants

\begin{tabular}{lcc}
\hline $\begin{array}{l}\text { Sample, Sizes } \\
\text { Determinants }\end{array}$ & Population Size & Required Samples Size \\
\hline Yamane Table & $25,000-49,999$ & 394 \\
Krejcie \& Morgan Table & $40,000-49,999$ & 388 \\
Cochran s formula & $50 \%(\mathrm{p}=0.5)$ max variability & 384 \\
Cochran formula & a finite population of 48,479 & 381 \\
Considered Samples & In this study & 432 \\
\hline
\end{tabular}

The random procedure conducted both in selection central senatorial zone and the six LGAs in this study were pen and paper all through. This involves writing names, wrap, mixed and shaken up than invite the neutral persons to pick up (Creswell \& Clark, 2017; Yamane, 1967; Cochran, 1977; Krejcie $\&$ Morgan, 1970; Hashim, 2010). This was done in such a way that all were given an equal chance to be selected in the sample and eliminate any forms of bias. The sample size determination is an important step that leads to the selection of respondents. In selecting respondents, systematic sampling technique was employed using the list of parents via their children register obtained from the REAECD centres. The sampling processes up to selection respondents was termed as 'multistage systematic random sampling techniques'. The area coverage of the research and volume of data collected suggested multistage sampling technique (Ary et al., 2006; Creswell \& Clark, 2007; Fine, Torre, Boudin, Bowen, Clark, Hylton, Martinez, Roberts, Smart, Upegui, 2003). As recommended by Fraenkel et al. (2011), that, "the participants in systematic random sampling procedure are selected from a list of the population in the manner that every nth is selected. The criteria were used on the list of all parents in the sampled villages with REA-ECD centres. In each of the 6-selected LGAs, there are 36 households selected based on systematic random sampling techniques. This makes a total of 216 households from sampled villages of this study.

\section{Data Collection and Analyses Procedure}

This study is quantitative, therefore, used a fully structured questionnaire for data collection. The instrument used was prepared through adaption from existing instruments. The instruments consist of three major parts; the first part was respondents' backgrounds, second part; households' backgrounds, and third part; REA-ECD acceptance domains. A total of 432 of the instruments were administered to the respondents through the trained enumerators. The data collection were including use of face-toface questioning the respondents and completing the questionnaires. This was due to the nature of rural areas, where not all or everyone can read and write in filling the questionnaire appropriately. This is part of the training the enumerators were given, for strictly adhered to the guidelines of the data collection. The principal researcher was moving from one area to another to monitor the conduct of data collection daily. This helps to ensure that, the enumerators have adhered to guidelines and provided the needed support to both enumerators and respondents were necessary.

From the total questionnaires administered and filled throughout the survey, 405 valid were used in analyses. These were after treatment of outliers and missing value cases. In keeping to the aim of this study, after all, preliminary descriptive analysis of the data, inferential analyses were conducted. Binary Logistic Regression (BLR) was used to determine the likelihood of each of the household 
background variables in predicting high REA-ECD acceptance. Finally, predictors of the likelihood of high REA-ECD acceptance were identified. However, multicollinearity test among independent variables of the model was performed through a correlation matrix. This allows looking at the high correlation between independent variables (usually 0.50 and above), as such one of the highly correlated variables was dropped before the Model analysis. The BLR was chosen due to dependent variable was made dichotomous; high REA-ECD acceptance=1 (Khandoker et al., 2017; Copas, 1983; Altman \& Andersen, 1989; Derksen \& Keselman, 1992; Huguet et al., 2017). BLR choice was also due to independent variables were on different measurements. BLR measures independent variables of whatever measurement to predict the likelihood of an event (Snow David et al., 1986; Khandoker et al., 2017). In this paper, 5-type of statistics were considered for decision making on BLR results. The Omnibus Test of Model Coefficients, Hosmer and Lemeshow test of goodness of fit, Wald Chi-Square statistics, Logistic Regression Coefficient (B) and Log odds or Exp (B) (Altman \& Andersen, 1989; Hair et al., 2010; Copas, 1983; Derksen \& Keselman, 1992; Hamdollah \& Baghaei, 2016; Lichstein, 2007).

This explained and considered the use of logistic regression models in this study because it is interesting to know how much variance in the dependent variable (DV) was explained by each component of independent variables in the Models (Copas, 1983; Derksen \& Keselman, 1992; Hair, Anderson, et al., 2010). Therefore, these are often preferable measurement to report in BLR. The variables in the model have accepted the BLR test, based on the model, the BLR equation for the model is as follows:

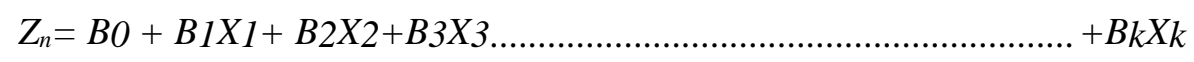

Note:

- $z$ is the logit and also called the log odds of the dependent variable

- $n$ is the number of Models from 1-4

- $B_{0}$ is the constant

- there are $k$ independent variables

- the " $B$ " terms as the logistic regression coefficient, or parameter estimates

- $\operatorname{Exp}(B)$ is the odds ratio for each IV. The odds ratio is the factor by which the IVs increases or decreases the log odds of the DV

\section{Findings}

The BLR statistics obtained $p \leq 0.05$ in Omnibus Test of Model Coefficient. This indicates that the Model is significant to explain the likelihood of high REA-ECD acceptance. Hosmer and Lemeshow test of goodness of fit statistic at $p>0.05$, indicates the predictor variables in the Model were linearly related to $\log$ odds of high REA-ECD acceptance. This also showed the Model variables were sufficient and fit to predicts the likelihood of high REA-ECD acceptance. The model was constructed as a Household Background Model (HBM), comprising nine (9) main variables. The variables are years in marriage, education level, a secondary source of income, household size, household income, presence of sons, presence of daughters, school type and age of school entry. From these variables, three are on scales data while the remaining are on categorical data. This makes the Model have a total of nineteen (19) variable components. Ten variable components were significantly $(p<0.05)$ predicted high REA-ECD acceptance in the Model. Therefore, it was concluded that HBM was significant to predict the likelihood of high REA-ECD acceptance. Hence, HBM rejected Ho, that there exist no households' background variables predicted the likelihood of high REA-ECD acceptance. The below was an equation of the Model.

$$
\begin{gathered}
Z_{2}=-0.809+\mathbf{1 . 0 4 9}+\mathbf{0 . 7 8 7}+\mathbf{2 . 5 2 2}-\mathbf{0 . 2 1 5}+\mathbf{1 . 1 8 1}+0.937+0.697+0.454-\mathbf{0 . 8 8 6}-\mathbf{1 . 3 9 1}+0.105+\mathbf{0 . 0 0 1}+ \\
0.687+\mathbf{1 . 6 9 2}+\mathbf{1 . 9 4 1}-0.164-0.796-1.029-0.657
\end{gathered}
$$

Equation: Households Background Model 
The paper reported all ten significant variables components; however, the main discussion was focus only on the presence of daughters as a predictor of high REA-ECD acceptance in HBM. The significant variables were included eight (8) as categorical, that are primary, secondary and tertiary education levels, presence of daughters, animal husbandry, processed food business and a secondary source of income as well as4-years and 5-years school entry age. The scale variables were the number of years in marriage and household monthly income as all presented in the Model Table 2 below.

Table 2: Wald Chi-Square Statistics of Model; Dependent Variable=1

\begin{tabular}{lllllll}
\hline $\begin{array}{l}\text { Household Background } \\
\text { Model (HBM) } \mathrm{n}=216\end{array}$ & $B$ & S.E. & Wald & d.f. & Sig. & Exp $(B)$ \\
\hline HOHPE & 1.049 & 0.558 & 3.538 & 1 & 0.050 & 2.567 \\
HOHSE & 0.787 & 0.470 & 2.811 & 1 & 0.049 & 2.861 \\
HOHTE & 2.522 & 1.144 & 4.862 & 1 & 0.027 & 12.450 \\
HOHYM & -0.215 & .049 & 19.531 & 1 & 0.000 & 0.806 \\
HOHPT & 1.181 & 0.581 & 4.131 & 1 & 0.042 & 3.258 \\
HOHAG & 0.937 & 0.574 & 2.667 & 1 & 0.102 & 2.552 \\
HOHPS & 0.697 & 1.53 & 0.207 & 1 & 0.649 & 2.007 \\
HOHAS & 0.454 & 1.513 & 0.07 & 1 & 0.792 & 1.491 \\
HOHAH & -0.886 & 0.399 & 4.946 & 1 & 0.026 & 0.412 \\
HOHFP & -1.391 & 0.492 & 8.000 & 1 & 0.005 & 0.249 \\
HOHSZ & 0.105 & 0.125 & 0.697 & 1 & 0.404 & 1.110 \\
HOHMI & 0.001 & 0.000 & 8.462 & 1 & 0.004 & 1.000 \\
HOH3Y & 0.687 & 0.467 & 2.168 & 1 & 0.141 & 1.988 \\
HOH4Y & 1.692 & 0.661 & 6.561 & 1 & 0.010 & 5.431 \\
HOH5Y & 1.941 & 0.477 & 16.586 & 1 & 0.000 & 6.963 \\
HOH6Y & -0.164 & 0.518 & 0.101 & 1 & 0.751 & 0.848 \\
HOHRE & -0.796 & 1.199 & 0.44 & 1 & 0.507 & 0.451 \\
HOHPR & -1.029 & 1.208 & 0.725 & 1 & 0.394 & 0.357 \\
HOHISL & -0.657 & 1.237 & 0.282 & 1 & 0.595 & 0.518 \\
CONSTANT & -0.809 & 2.15 & 0.142 & 1 & 0.707 & 0.445 \\
\hline
\end{tabular}

Notes The bolded variables of the model were significant predictors.

HOHPE=Pri. Educ. level

HOHSE=Sec. Educ. level

HOHTE=Tertiary Educ. level

HOHYM=Years in marriage

HOHPT $=$ Present of daughters

HOHAD=Above-two Daughters

HOHPS= Present of Son

HOHAS=Above-two Son

HOHAH=Animal Husbandry

HOHFP=Food Processing

HOHSZ=Household size

HOHMI = Monthly income

HOH3Y $=3-$ Year School entry

HOH4Y = 4-Year School entry

HOH5Y =5-Years School entry

HOH6Y=6-Year Sch entry

HOHRE=Reggio Emilia Center

HOHPR=Primary School

HOHISL=Islamic School

The education levels significantly predicted the likelihood of high REA-ECD acceptance, in Wald Chi-Square statistic of the Model. Compared to households with primary education level, the household with a tertiary level of education had 12.5 times (odds=12.45) more likelihood of high 
REA-ECD acceptance. By implication, this result means the households with parents who attended tertiary education level would have 12.5 times more likely for high REA-ECD acceptance.

The Model had presented the unique interesting finding which shows the presence of daughters in households significantly predicted the likelihood of high REA-ECD acceptance. The Wald Chi-Square statistic on the presence of daughters was $p<0.05$ in the Model. The presence of daughters in the householdhad2.26 times (odd=3.258) more likelihood of high REA-ECD acceptance. Though, information about children was representing the entire family and or household. However, it was surprising that the presence of a daughter or two in a rural household will improve the likelihood of high REA-ECD acceptance. This implies that having a daughter or two in family increase the chances of high REA-ECD acceptance by their parents. The age of school entry was also significantly predicted the likelihood of high REA-ECD acceptance in the Wald Chi-Square statistic in HBM. In comparing to three-year school entry, five-year school entry age had 6.0 times (odds=6-963) more likelihood of high REA-ECD acceptance among the households. Four-year school entry compared to three-year school entry had 4.4 times (odds=5.43) more likelihood of high REA-ECD acceptance. However, household's monthly income significantly predicted the likelihood of high REA-ECD acceptance, in the same way, as it predicted the likelihood of low REA-ECD acceptance (odds=1.000).

On the other hand, the animal husbandry and processed food business as the components of households' secondary sources of income significantly predicted less likelihood of REA-ECD acceptance. Animal husbandry had reduced the likelihood of high REA-ECD acceptance by 59 percent with (odds $=0.412$ with negative $B$ ). Furthermore, the processed food business had reduced the likelihood of high REA-ECD acceptance by 75 percent (odds $=0.249$ with negative $B$ ). The number of years in marriage has also significantly predicted the less likelihood of high REA-ECD acceptance. Years in marriage had reduces the likelihood of high REA-ECD acceptance by 19 percent (odds $=0.81$ negative $B$ ). However, remaining variables in the model were not significant in predicting the likelihood of high REA-ECD acceptance as depicted in the Model table above.

\section{Discussion}

The most exceptional outcome from the Model of this study was having a daughter or two, which was appeared important in high REA-ECD acceptance. The finding was the fulcrum of this study and it can be a baseline of its periodical conduct within the rural communities. This would support the current global trends seeking to remove any gender barriers and shift the mindset from gender equality to gender equity. The target is to leave gender equality to focus on providing men and women with the same and equal opportunities in the legal frameworks. However, gender equity should work to correct the historical harms that have left women behind through societal restrictions on various opportunities including education. Gender equity may also provide women with the tools to succeed through such education program that offers them conditional cash transfers. The strong focus on gender equity may on short term bridges the inequality gaps by the provision of laws and policies on gender-focused programs that not only level the playing ground but also work to change the cultural setting as well as give more supports to women and girls to be educated. This cultural shift requires efforts from all leaders and individual community members. Therefore, the paradigm ship to understand the differences between gender equity and equality is essential in providing supports to girls and women. This is not just by offering them the same opportunities with men but recognizing the lingering barriers that prevent those opportunities from becoming a reality for countless females.

Having a daughter or two in this study is an imperative finding though, it may seem a controversial issue to the conservative individuals, but itis as well merit to the development community. Although rural areas of the northern state area total patriarchal society with $100 \%$ controlled by males. The patriarchal way of life in rural society was described by Zumilah (2010) look as it reduces the quality of sons' human capital in rural Malaysia. In such a society where the human capital quality of sons was reduced, the traditional gender perspective may view the human capital of daughters on the other hand, in total dangerous position. This is because the sons in a patriarchal system have the choice of increasing their human capital quality (Shirin \& Kihara, 2013), through academic achievement 
(Abdullahi et al., 2013; Zumilah, 2010). However, the traditional gender ideology perspective of rural parents and larger society constrained daughters from having such a choice. From this perspective, the ideology of both parents and larger society particularly in rural areas contributed to the debate on less importance of daughters' education. The issue may have similarity but differs from what (Zumilah, 2010) discovered on having "sons as an issue" in Malaysian rural society. Her finding indicates that having sons is a problem to rural enterprise development among rural Malay family.

However, historically rural parents and society at large in northern Nigeria view daughters as helpers in the households chores (Aisha, 2016). Also, others view daughters as an additional burden in households and not like sons, the daughters at one time will marry to another household but leaving out some responsibility of her with her family. Their notion was that the daughter at all time need support from her family, even when she was finally married out to another family (Ibrahim, 2014). This type of situation can negatively affect females and girls' education in such a society, except a certain intervention, were made. This is because females' education though with intervening influences not only future education, next girls generation but the entire society (Abdullahi et al., 2013; Aisha, 2016; Aisha \& Yahuza, 2018). However, most parents including the females were wishing to have sons especially firstborn who will be ambitious and can provide some supports to the family. The parents also believe that daughters are not future responsible for general supports of the family as their sons do. The said finding from this study contradicted this notion that traces its based on traditional gender ideology. However, was supported being in line with (Roe \& Morris, 2004) on capabilities of women in the alternative model of responsibility in the supports of family. Unfortunately, these works discovered that most services established to support and protect families have been problematic, contradictory and unhelpful for mothers and daughters.

The presence of daughters in this study is an added advantage in households being a significant predictor of the likelihood of high REA-ECD acceptance. This is because the program as a support service empowers more female parents with employment opportunity. Thus, in the long term, would facilitate not only the development of the rural family but also the larger society and nation at large. This finding may be linked to the current intervention of girls' education empowerment program (GEEP) in the study area, in which most female parents acquire Nation Certificate in Education (NCE) as high educational qualification. The daughters being with their educated mothers even in the case of divorce or fathers' death (Abdullahi et al., 2013; Aisha, 2016; Ibrahim, 2014; Sarki, 2015), will continue schooling under their mother's supports. Although, in general, females keep struggle with equality like in the issues of wages gap. This is because patriarchy is a never-ending fight rooted in the name of everyone should stay in the area they are expected. However, in the society of today, females in most parts of the world have access to education and jobs though not like their male counterparts. These waves will gradually be annexed even in the rural areas, were some females parents are coming up so far (Broadband Commission Working Group on the Digital Gender Divide, 2017). This is a new gender paradigm shift and conversation for most males that their stereotypes are becoming more common for females and accepted in society. This might not be unconnected to the presence of daughters as a predictor of the likelihood of high REA-ECD acceptance instead of sons' presence. Another reason that may highlight this finding was being daughters more transformational in leadership style (Zainalaludin, Jamaluddin \& Abd Shukor, 2017), and more relationship-oriented in the management (Zumilah, 2010). While the sons mostly portray the opposite, they are growthoriented, reckless in opportunity and wild in taking power and leadership (Zainalaludin, Jamaluddin \& Abd Shukor, 2017) from their male parents.

In the rural area of Hausa land of northern Nigeria, this finding may seem in controversies as a new gender paradigm shift. This study observes some female-headed households also a new gender paradigm shift in the Hausa land region, as it is not common after death or divorce, for a woman to stay alone with her children (Abdullahi 2013). However, this issue might not be unconnected with the presence of the mass killing of rural males by bandits and gangsters and leaving females as widows with several children (Audu, Yahya \& Bassi, 2006; Olotuah \& Olotuah, 2016; Izugbara \& Ezeh, 2010; Munro et al., 2011; Pierce, 2007; Sarki, 2015). What was usually known, the children and female parents in the event of death or divorce will remain under the custody of fathers' family or relatives 
(Sarki, 2015). This is generally obvious as there were concerns and generosity over females and children especially daughters by society for the lost their husbands and parents.

\section{Conclusion and Implication}

Conclusion of this paper was that, having daughters not sons among rural households as a significant predictor of high REA-ECD acceptance portrayed a greater breakthrough. It is a revolutionary process in curtailing traditional gender role cluster and social gender-based stratification which rooted in the life of rural society. This was very clear by indicating the daughters instead of sons as a predictor of the likelihood of high RAE-ECD acceptance which involved the future generation education. This also indicates that the traditional gender roles ideology can gradually change if the practices of the patriarchal system were kept corroding and rusting. The gender and development efforts particularly, through education and further researches, may positively increase the human capital quality of future mothers and daughters. This was very possible when policies and more studies were embedded in continuous. Improving gendered education and indiscrimination in indigenous knowledge and skills as well as entrepreneurial skills such as that of cooking, handcrafting, and weaving among all children will be very vital. This may also improve the households' family democratic setting and attendance to the tertiary level of education. The system would change to become more rational in decision making, more democratic in the household and the society at large. These may also result in the acceptance of new ideas, practices, programs and systems for gendered sustainable development. The study was limited to a single culture of rural northern Nigeria, more studies with a similar variable need to be conducted using a multicultural perspective. A longitudinal study in future is required to ascertain the existence of the development over time.

\section{References}

Abbas, Ali Ibrahim, and Hadiza Mali Bukar. (2017). "Perspectives on Gendered Education Development in Nigeria: Evidence from Akademia Baru Journal of Advanced Research in Perspectives on Gendered Education Development in Nigeria: Evidence from Yobe State, Nigeria, 2009-2015." Journal of Advanced Research in Social and Behavioural Sciences 9 (1): $57-74$.

Abdu, Ado, Ahmad Hariza Hashim, and Abu-Samah Asnarulkhadi. (2014). "Relationship between Background Characteristics and Residential Satisfaction of Young Households in Unplanned Neighbourhoods in Kano, Nigeria." Journal of Humanities and Social Science 19 (10): 138-45. https://doi.org/10.9790/0837-19108138145.

Ibrahim Abdullahi. (2013). "Empowering Rural Girls through Education: Way of Reducing Vulnerability and Improving Family Economic Wellbeing in Rural Northern Nigeria." IOSR Journal Of Humanities And Social Science 18 (1): 57-61. https://doi.org/10.9790/08371815761.

Abdullahi, Ibrahim, and Sani Maiunguwa. (2014). "Gender Parity and Poverty in Rural Households of Nigeria: Empowerment as A Way Forward." IOSR Journal of Humanities and Social Science 19 (1): 95-99. https://doi.org/10.9790/0837-19139599.

Abdullahi, Ibrahim, Zumilah Zainalaludin, and Laily Bint Paim. (2013). "A Distinct Gap in Gendered Impact of Girls Education Empowerment on Family Wellbeing in Rural Katsina, Northern Nigeria." International Journal of Humanities and Social Science Invention 2 (4).

Abu-Dalbouh, Hussain Mohammad. (2013). "A Questionnaire Approach Based on the Technology Acceptance Model for Mobile Tracking on Patient Progress Applications." Journal of Computer Science 9 (6): 763-70. https://doi.org/10.3844/jcssp.2013.763.770.

Adamu, Abdullahi. (2017). "Economic Analysis of Resource Conservation and Households' Preferences of Attributes in Hadejia-Nguru Wetlands, Nigeria." Ph.D. Thesis University Putra Malaysia.

Aisha, Ibrahim Ningi. (2016a). "Influence of Socio-Cultural Values on Girl-Child Education in Yobe State, Nigeria." PhD. Thesis University Putra Malaysia. http://www.upm.edu.my/about_us/OurLoc?LANG=en. 
Aisha, Ibrahim Ningi, and Hamza bubakar Yahuza. (2018). "Content Analysis of Some Historical Facts and the General Position of Islam on Girls Education." International Journal of Humanities \& Social Science Studies (IJHSSS) 6959 (36): 8-12. https://doi.org/10.29032/ijhsss.v5.i1.2018.36-43.

Al-Sayyed, Fareed, and Baker Abdalhaq. (2016). "Interventional Factors Affecting Instructors Adoption of E-Learning System: A Case Study of Palestine." Journal of Theoretical and Applied Information Technology 83 (1): 119-37. https://doi.org/10.1287/mnsc.46.2.186.11926.

Alharbi, Saleh, and Steve Drew. (2014). "Using the Technology Acceptance Model in Understanding Academics' Behavioural Intention to Use Learning Management Systems." International Journal of Advanced Computer Science and Applications 5 (1). https://doi.org/10.14569/IJACSA.2014.050120.

Alizadeh, Shahla, Mansor B Abu Talib, Rohani Abdullah, and Mansor Mariani. (2011). "Relationship between Parenting Style and Children's Behavior Problems." Asian Social Science 7 (12): 195200. https://doi.org/10.5539/ass.v7n12p195.

Altman, Douglas G, and Per Kragh Andersen. (1989). "Bootstrap Investigation of the Stability of a Cox Regression Model." Statistics in Medicine 8 (7): 771-83.

Alto, Michelle, Elizabeth Handley, Fred Rogosch, Dante Cicchetti, and Sheree Toth. (2018). "Maternal Relationship Quality and Peer Social Acceptance as Mediators between Child Maltreatment and Adolescent Depressive Symptoms: Gender Di Ff Erences." Journal of Adolescence 63 (August 2017): 19-28. https://doi.org/10.1016/j.adolescence.2017.12.004.

Alvergne, Alexandra, Charlotte Faurie, and Michel Raymond. (2007). "Differential Facial Resemblance of Young Children to Their Parents : Who Do Children Look like More ?" Natural Resource Management 28: 135-44. https://doi.org/10.1016/j.evolhumbehav.2006.08.008.

Amali, I. o., Bello Muhinat, and P Ijeoma. (2016). "An Assessment of Pre-Primary School." European Scientific Journal 8 (8): 73-82.

Amina, Ibrahim Inkani. (2015). "Households' Vulnerability and Adaptation To Water Scarcity in Rural Areas, Katsina State, Nigeria." Ph.D Thesis, University of Narobi, Kenya.

Anna, Baldacchino. (2010). "Localizing Reggio: Adapting the Reggio Emilia Approach to Early Childhood Education in Three Childcare Centres on Prince Edward Island." Msc Thesis, Universityof Prince Edward Island.

Anne, B. Onyekwuluje. (1998). "Multiculturalism, Diversity and Impact Parent and Schools Have on Societal Rece Relationship.” The School Community Journal 8 (2).

Arthur, Skye Mac. (2018). "An Investigation of Foundation Phase Teachers' Classroom Practices to Promote Student Engagement as an Inclusive Pedagogy."

Ary, D, L C Jacobs, A Razavieh, and C Sorensen. (2006). "Introduction to Research in Education: Thomson Wadsworth." Belmont, $C A$.

Audu, B M, S J Yahya, and A Bassi. (2006). "Knowledge, Attitude and Practice of Natural Family Planning Methods in a Population with Poor Utilisation of Modern Contraceptives." Journal of Obstetrics and Gynaecology 26 (6): 555-60.

Banerjee, Amitav, and Suprakash Chaudhury. (2010). "Statistics without Tears: Populations and Samples." Industrial Psychiatry Journal 19 (1): 60.

Bekker-Grob, Esther W de, Bas Donkers, Marcel F Jonker, and Elly A Stolk. (2015). "Sample Size Requirements for Discrete-Choice Experiments in Healthcare: A Practical Guide." The PatientPatient-Centered Outcomes Research 8 (5): 373-84.

Broadband Commission Working Group on the Digital Gender Divide. (2017). "Recommendations for Action: Bridging the Gender Gap in Internet and Broadband Access and Use." Broadband Commission Working Group on the Digital Gender Divide, under the Auspices of the United Nations (UN) Broadband Commission for Sustainable Development., no. March: 48.

Butler, Judith. (2004). Unduing Gender. New York and London: ROUTLEDGE NEW YORK AND LONDON.

Carter, Michael J. (2014). "Gender Socialization and Identity Theory.” Social Sciences 3 (1): 242-63. https://doi.org/10.3390/socsci3020242.

Christman, Dana E, and Rhonda L McClellan. (2012). "Discovering Middle Space: Distinctions of Sex and Gender in Resilient Leadership.” The Journal of Higher Education 83 (5): 648-70.

Cochran, W.O. (1977). Smrrpling TecIrniqun. 3RD Editio. New York.: John Wiley \&: Sons.

Cockerill, C a, S M Chilton, and W G Hutchinson. (2007). "Household Decision Making Models And 
The Value Of Child Farm Safety." Journal of Agricultural Econmic Society 81st Annual Conference, University of Reading, UK.

Conboy, Kieran, Guy Fitzgerald, and Lars Mathiassen. (2012). "Qualitative Methods Research in Information Systems: Motivations, Themes, and Contributions." European Journal of Information Systems 21 (2): 113-18.

Copas, John B. (1983). "Regression, Prediction and Shrinkage." Journal of the Royal Statistical Society: Series B (Methodological) 45 (3): 311-35.

Cox, E S, and R K Z Heck. (1998). "The Family as a Foundation of Our Free Society: Strengths and Opportunities.” The Entrepreneurial Family, 8-15.

Creswell, John W, and Vicki L Piano Clark. (2007). "Designing and Conducting Mixed Methods Research." Australian and New Zealand Journal of Public Health 31 (4): 388-388. https://doi.org/10.1111/j.1753-6405.2007.00096.x.

Creswell, John W, and Vicki L Plano Clark. (2017). Designing and Conducting Mixed Methods Research. Sage publications.

Dannhaeuser, Norbert. (1993). "The Survival of Family-Operated Firms under Developed Conditions: The Case of Hassfurt, Germany." The Journal of Developing Areas 27 (3): 307-28.

David, Sadker, Sadker Myra, and R. Zittleman Karen. (2014). "Still Failing at Fairness: How Gender Bias Cheats Girls and Boys in School and What We Can Do About It." Journal of Education and Educational Development 1 (1): 71-76.

David, Snow, Rochford Burke, Worden Steven, and Benford Robert. (1986). "Frame Alignment Processes, Micromobilization, and Movement Participation." American Sociological Review 51 (4): 464-81.

Derksen, Shelley, and Harvey J Keselman. (1992). "Backward, Forward and Stepwise Automated Subset Selection Algorithms: Frequency of Obtaining Authentic and Noise Variables." British Journal of Mathematical and Statistical Psychology 45 (2): 265-82.

Dermont, Clau, Karin Ingold, Lorenz Kammermann, and Isabelle Stadelmann-ste. (2017). "Bringing the Policy Making Perspective in : A Political Science Approach to Social Acceptance." Energy Policy 108 (May): 359-68. https://doi.org/10.1016/j.enpol.2017.05.062.

Ejieh, Michael U C. (2006). "Pre-Primary Education in Nigeria: Policy Implementation and Problems." Elementary Education Online 5 (1): 58-64.

"Factors in Fl Uencing Citizens ' Acceptance and Non-Acceptance of Wind Energy in Germany." (2018). Journal of Cleaner Production 175: 133-44. https://doi.org/10.1016/j.jclepro.2017.11.221.

Fairani, Ahmad, and Mansor Mariani. (2016). "Externalizing Behaviour Problem among Children Age Four and Below in Peninsular Malaysia." Asian Journal of Social Sciences \& Humanities 5 (1).

Fasona, Mayowa. (2014). "Gender Dimensions of Urban Commercial Farming in Lagos, Nigeria The High Rate of Poverty among Urban Households and The," no. January 2004.

Fernandez, Almudena. (2017). "Policies and Strategies to Reduce Vulnerability and Enhance Resilience."

Fine, M., Torre, M.E., Boudin, K., Bowen, I., Clark, J., Hylton, D., Martinez, M., "Missy,” Rivera, M., Roberts, R.A., Smart, P. and Upegui, D. (2003). "Participatory action. 2003. "Participatory Action Research: From Within and Beyod Prison Bars." In Qualitative Research in Psychology: Expanding Perspective in Methodology and Design, 173-98.

Fraenkel, Jack R, Norman E Wallen, and Helen H Hyun. (2011). How to Design and Evaluate Research in Education. New York: McGraw-Hill Humanities/Social Sciences/Languages.

Gandini, Lella. (2011). "Play and the Hundred Languages of Children: An Interview with Lella Gandini." Americal Journal of Play 4 (1): 1-18.

Garba, Hamza A. (2017). "The Impact of British Colonial Education on Northern Nigeria: The Construction of a pro- British Oriented Society." International Journal of Advanced Education and Research 2 (6): 43-49.

Gikonyo, Wamuyu, Zumilah Zainalaludin, and Jariah Masud. (2006). "Empowering Young Women through Micro-Enterprise Scaling-Up: A Case of Malaysian Rural Women." In Youth Employment Summit. Citeseer.

Gliner, Jeffrey A, George A Morgan, and Nancy L Leech. (2011). Research Methods in Applied Settings: An Integrated Approach to Design and Analysis. Routledge.

Hair, Joseph F., Rolph E. Anderson, Barry J. Babin, and Wiiliam C. Black. (2010). "Multivariate Data 
Analysis: A Global Perspective (Vol. 7).” Upper Saddle River, NJ: Pearson.

Hamdollah, Ravand, and Purya Baghaei. (2016). "Partial Least Squares Structural Equation Modeling with R." Practical Assessment, Research and Evaluation 21 (1): 1-16. https://doi.org/10.1108/ebr-10-2013-0128.

Hashim, Yusuf Alhaji. (2010). "Determining Sufficiency of Sample Size in Management Survey Research Activities." International Journal of Organisational Management \& Entrepreneurship Development 6 (1): 119-30.

Hsiao, Ju-Ling, and Rai-Fu Chen. (2016). “Critical Factors Influencing Physicians ' Intention to Use Computerized Clinical Practice Guidelines: An Integrative Model of Activity Theory and the Technology Acceptance Model." BMC Medical Informatics and Decision Making 16 (3): 1-15. https://doi.org/10.1186/s12911-016-0241-3.

Huguet, Alice, Anna-Ruth Allen, Cynthia E. Coburn, Caitlin C. Farrell, Debbie H. Kim, and William R. Penuel. (2017). "Locating Data Use in the Microprocesses of District-Level Deliberations." Nordic Journal of Studies in Educational Policy 3 (1): 21-28. https://doi.org/10.1080/20020317.2017.1314743.

Ibrahim, Abdullahi. (2014a). Imacts of Girls Education Empowerment Programme on the Economic Well-Being of Katsina Rural Society, Nigeria. MSc Thesis, University Putra Malysia.

Ibrahim, Aisha Ningi, Ahmad Tarmizi Talib, Laily Bint, Hj Paim, and Sarjit S Gill. (2015). "Cultural Dynamics of Child Labour in Yobe State Nigeria." Journal Of Humanities And Social Science 20 (5): 71-79. https://doi.org/10.9790/0837-20567179.

Ismail, Norisma Aiza, Jariah Masud, and Zumilah Zainalaludin. (2015). "Income Components and Poverty among Older Men and Women in Malaysia." ASIAN JOURNAL FOR POVERTY STUDIES (AJPS) 1 (1).

Izugbara, Chimaraoke O, and Alex C Ezeh. (2010). "Women and High Fertility in Islamic Northern Nigeria." Studies in Family Planning 41 (3): 193-204.

Jackie, Kirk. (2006). Education in Emergencies: The Gender Implication. Edited by Caroline Haddad. Second. Bangkok: UNESCO Asia and Pacific Regional Bureau for Education.

Jorge, García Luis, J.James Heckman, and Anna L Ziff. (2017). "Gender Differences in the Benefits of An Influential Early Childhood Program.” 23412. MA 02138. https://doi.org/10.3386/w23412.

Khandoker, Ahsan H., Haitham M. Al-Angari, Kinda Khalaf, Sungmun Lee, Wael Almahmeed, Habiba S. Al Safar, and Herbert F. Jelinek. (2017). "Association of Diabetes Related Complications with Heart Rate Variability among a Diabetic Population in the UAE." PLoS ONE 12 (1): 1-16. https://doi.org/10.1371/journal.pone.0168584.

Komendantova, Nadejda, and Antonella Battaglini. (2016). "Energy Research \& Social Science Beyond Decide-Announce-Defend ( DAD ) and Not-in-My-Backyard ( NIMBY ) Models? Addressing the Social and Public Acceptance of Electric Transmission Lines in Germany." Energy Research \& Social Science Jo 22: 224-31. https://doi.org/10.1016/j.erss.2016.10.001.

Krejcie, Robert V, and Daryle W Morgan. (1970). "Determining Sample Size for Research Activities." Educational and Psychological Measurement 30 (3): 607-10.

Kretchmar, Jennifer. (2009). "Gender Socialization: Sex, Gender and Sexuality." In , 8. EBSCO Publishing Inc.

Lichstein, Jeremy W. (2007). "Multiple Regression on Distance Matrices: A Multivariate Spatial Analysis Tool." Plant Ecology 188 (2): 117-31.

Lim, Weng Marc, and Ding Hooi Ting. (2012). "E-Shopping: An Analysis of the Technology Acceptance Model." Modern Applied Science 6 (4): 49-62. https://doi.org/10.5539/mas.v6n4p49.

Lindsey, Eric W., and Jacquelyn Mize. (2001). "Contextual Differences in Parent-Child Play: Implications for Children's Gender Role Development." Sex Roles 44 (3-4): 155-76. https://doi.org/10.1023/A:1010950919451.

Liu, Zi Yu. (2014). "Exploring User Acceptance and Intension of Taxi-Hailing App in Shanghai." An Analysis of Technology Acceptance Model, no. September 2014: 1.

Mader, Katharina. (2013). "The Gendered Nature of Intra-Household Decision Making in and across Europe."

Mclean, George F, and Joseph Kenny. (2014). The Idea of a Nigerian University: Vol. 16.

Meryem, Casu Birinci. (2018). "Teacher in Reggio Emilia Approach : Educational Needs and Views." EURASIA Journal of Mathematics, Science and Technology Education 14 (1): 279-90. 
https://doi.org/10.12973/ejmste/79800.

Miatta, Bombali. (2017). "Building a Pathway from Demonstration to Scale-up - Promoting Early Childhood Development in Sierra Leone."

Mohammed, Kabir, David Chapola Nggada, and Yusuf Abdullahi. (2013). "The State of Nigerian Female Education in the Post Colonial Era; With Reference To Some Northern States." International Journal of Pharmaceutical Science Invention ISSN (Online 2 (11): 2319-6718. www.ijhssi.org.

Moss, Peter. (2006). "Structures, Understandings and Discourses: Possibilities for Re-Envisioning the Early Childhood Worker." Contemporary Issues in Early Childhood 7 (1): 30-41. https://doi.org/10.2304/ciec.2006.7.1.30.

Munro, Alistair, Bereket Kebede, Marcela Tarazona-Gomez, and Arjan Verschoor. (2011). "The Lion's Share: An Experimental Analysis of Polygamy in Northern Nigeria." Available at SSRN 1821283.

Navarro Sada, Alejandra, and Antonio Maldonado. (2007). "Research Methods in Education. -by Louis Cohen, Lawrence Manion and Keith Morrison." Taylor \& Francis.

NECE, National Center. (2016). Healthy Gender Development and Young Children: A Guide for Early Childhood Programs and Professionals.

Nupponen, Hannele. (2005). "Leadership and Management in Child Care Services: Contextual Factors and Their Impact on Practice."

Nura, Aliyu Kabuga, and Usman Musa Adamu. (2017). "Empirical Analysis of Rural Poverty in Katsina State, Nigeria." Yobe Journal of Economics 2 (1).

Odiagbe, Sunny Ighalo. (2015). "The National Minimum Standard on Early Child Care Centers (ECCC) in Nigeria and the Status of Pre-Primary Education in Uhunmwode Local Government Area of Edo State." American Journal of Educational Research 3 (4): 399-405. https://doi.org/10.12691/education-3-4-3.

Olotuah, Abiodun Olukayode, and Damilola Esther Olotuah. (2016). "Space and Cultural Development in Hausa Traditional Housing." International Journal of Engineering Sciences \& Research Technology 5 (9): 654-59. https://doi.org/10.5281/zenodo.155089 ABSTRACT.

Pence, Alan, and Emily Ashton. (2015). "Early Childhood Research in Africa: The Need for a Chorus of Voices." The SAGE Handbook of Early Childhood Research, 380-97. https://doi.org/10.4135/9781473920859.n23.

Pierce, Steven. (2007). "Identity, Performance, and Secrecy: Gendered Life and the" Modern" in Northern Nigeria." Feminist Studies 33 (3): 539-65.

Rinaldi, Carlina, The Hundred Languages, Children Reggio, The Image, Child The, Reggio Emilia, Reggio Emilia, The Role, Environment Through, and Reggio Emilia. n.d. "Basic Principles of the Reggio Emilia Approach."

Roberta, Nelson. (2000). "Application of Reggio Emila Approach to Environments in USA." Univesity of Nevraska.

Roe, Miranda, and Anne Morris. (2004). "The Capabilities of Women: Towards an Alternative Model of 'Responsibility' in Supporting Families and Children," no. October.

Salami, Ishola Akindele, Early Childhood, and Education Unit. (2016). "Nigerian Early Childhood Education Policies and Practices for Sustainability." European Journal Research and Reflection in Educational Sciences 4 (5): 71-85.

Santín, Mercè Fernández, and Maria Feliu Torruella. (2017). "Reggio Emilia: An Essential Tool to Develop Critical Thinking in Early Childhood" 6 (1): 50-56. https://doi.org/10.7821/naer.2017.1.207.

Sarki, Zakariyya Muhammad. (2015). "The Portrait of Family Size in the Hausa Home Videos: Culture or Economy?" International Journal of Physical and Social Sciences 5 (7): 274-82.

Shirin, Rai, and Jayne Kihara. (2013). "Equal Participation of Women and Men in Decision-Making Processes, with Particular Emphasis on Political Participation and Leadership." United Nation Division for the Advancement of Women. Vol. 32. https://doi.org/10.25148/etd.FI10022504.

Sumita Parmar, Ragini SahaiDeepa Puneetha. (1996). "Gender Socialization Module: Gender from a Developmental Perspective."

Surendran, A, and C Sekar. (2010). "An Economic Analysis of Willingness to Pay (WTP) for Conserving the Biodiversity." International Journal of Social Economics.

Suzana, Shahar, Nur 'Asyura Adznam Siti, Suriah AbdulRahman, Mod. Yusoff NoorAini, Zaitun 
Yassin, Fatimah Arshad, Noor Sakian Mohamed Ibrahim, Mohmad Salleh, and Asnarulkhadi Abu-Samah. (2012). "Development and Analysis of Acceptance of a Nutrition Education Package among a Rural Elderly Population: An Action Research Study." BMC Geriatrics 12 (24): $1-9$.

Udenigwe, Ogochukwu. (2013). "Managing the Impacts of Full Day Kindergarten on Rural Childcare Centres in Ontario." Thesis.

UNECEF, Nigeria. (2015). "Nigerian Educational Research and Development Council (Nerdc)."

UNESCO, IIEP. (2019). Mainstreaming Early Childhood Education into Education Sector Planning: The Rationale for Investing in Pre-Primary. UNESCO.

UNESCO, Intternational Bureau. (2007). "Country Profile on the Education for All Global Monitoring Report 2007 Strong Foundations: Early Childhood Care and Education Nigeria." UNESCO.

UNICEF, Nigeria. (2018). "UNICEF 2017 Annual Report on Nigeria." https://www.unicef.org/about/annualreport/files/Nigeria_2017_COAR.pdf.

Wallang, Muslimmin. (2018). Determinants That Influence Citizen' s Usage of Different EGovernment Services : A Malaysian Case Study. PhD Thesis, Unuversity of Queensland.

Wersebe, Hanna, Roselind Lieb, Andrea H Meyer, Jürgen Hoyer, Hans-ulrich Wittchen, and Andrew T Gloster. (2017). "Changes of Valued Behaviors and Functioning during an Acceptance and Commitment Therapy Intervention.” Journal of Contextual Behavioral Science 6 (1): 63-70. https://doi.org/10.1016/j.jcbs.2016.11.005.

Wycliff, Samuel. (2014). A Study of the Establishment and Growth of Private Schools in Katsina, 1980-2010. Master Thesis Ahmadu Bello University, Zaria, Nigeria,

Yakubu, Sani Gombe. (2017). Moderating Effect of Gender on the Relationships Between Extension Worker Availability, Individual Factors and Empowerment Among Members of Self-Help Groups in North-Eastern Nigeria. PhD Thesis, University Putra Malaysia.

Yamane, T. (1967). "Research Methods: Determination of Sample Size."

Zainalaludin, Zumilah, Askiah Jamaluddin, and Abd Shukor. (2017). "Gender and Vulnerable Types among Vulnerable Member in Malaysia Fisheries and Aquaculture Community." International Journal for Studies on Children, Women, Elderly And Disabled 2: 32-37.

Zakiah, Adun, Half K. Mohamad, Zanalaludin Zumilah, and Sharif M. D. Mohamed. (2015). Best Aquacultural Practices for Gender Analysis among Micro \& Small Scale Aquaculture Operators. World Aquaculture Conference, Jeju, South Korea.

Zumilah, Zainalaludin. (2010). Indicators of Micro Enterprise Development for Small Family Business in Rural Peninsular Malaysia. PhD Thesis, University Putra, Malaysia. 